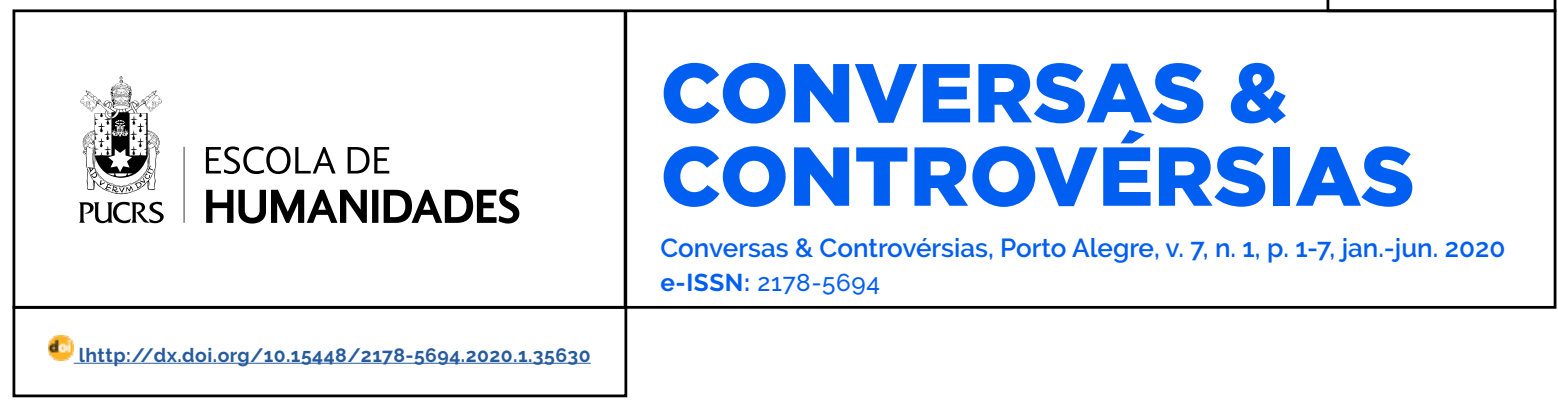

SEÇÃO: DOSSIÊ

\title{
Em condição de cidadania ou cidadania sob uma condição? Reflexões sobre a aplicação de medidas socioeducativas e o direito à cidadania no Brasil
}

\author{
On condition of citizenship or citizenship on condition? Reflections on the application of \\ socio-educational measures and the right to citizenship in Brazil
}

\section{Francielly Silva Costa} Alves Rocha ${ }^{1}$ orcid.org/0000-0002-5.954-2272 franciellycostaalves@hotmail.com

Recebido em: 11 set. 2019. Aprovado em: 6 mai. 2020. Publicado em: 17 set. 2020 .
Resumo: O presente artigo busca refletir sobre a aplicação das medidas socioeducativas no Brasil e a construção da cidadania no sistema jurídico brasileiro por meio de uma análise antropológica sobre a legislação da politica de atendimento à criança e ao adolescente e os dados sobre a aplicação efetiva dessas no Rio de Janeiro. Para a compreensão desse processo, realizou-se um estudo acerca da história das primeiras legislações que fundamentaram o atendimento a esse segmento no País, desde o primeiro Código Criminal até os dias atuais, com a implementação do Estatuto da Criança e do Adolescente, em 1990. Com a análise da proposta de tornar crianças e adolescentes cidadãos com proteção integral, buscamos compreender como a responsabilidade penal juvenil cria contradições ao exercício efetivo dessa política a favor das crianças e dos adolescentes evidenciando nas práticas do sistema de justiça a forma como a igualdade juridica é construida no Brasil.

Palavras-chaves: Cidadania. Medidas socioeducativas. Direitos sociais. Conflitos.

Abstract: This article seeks to reflect on the application of socio-educational measures in Brazil and the construction of citizenship in the Brazilian legal system through an anthropological analysis on the legislation of the policy of child and adolescent care and the data on their effective application in Rio. of January. To understand this process, a study was conducted on the history of the first legislations that supported the service to this segment in the country, from the first Criminal Code to the present day with the implementation of the Child and Adolescent Statute in 1990. The analysis of the proposal to make children and adolescents into citizens with full protection seeks to understand how juvenile criminal responsibility creates contradictions to the effective exercise of this policy in favor of children and adolescents, highlighting in their practices the way legal equality is built in Brazil. Keywords: Citizenship. Socio-educational measures. Social rights. Conflicts.

\section{Introdução}

No presente artigo buscamos refletir sobre a construção da cidadania no sistema jurídico brasileiro e o atendimento à criança e ao adolescente no País. Recentemente uma decisão do Supremo Tribunal Federal (STF) trouxe ao debate a questão da taxa de ocupação das unidades de internação de estados brasileiros destinados aos adolescentes em conflito com a lei. Ao conceder um habeas corpus coletivo contra a superlotação no sistema, o ministro Edson Fachin pôs em evidência não somente a falta de vagas, mas o problema da aplicação de medidas socioeducativas. 
A associação entre violência, juventude e pobreza que está presente no imaginário urbano (Paula 2011, 1) tem sido reforçada constantemente, assim como o mal-estar causado pelo envolvimento desses em atos ilícitos pondo a preocupação da sociedade civil com a forma como estes jovens e adolescentes são tratados nas instituições em segundo plano. Dessa forma, a legislação de atendimento à criança e ao adolescente com a proposta de torná-los cidadãos com proteção integral tem sido marcada por uma responsabilidade penal juvenil com contradições ao exercício efetivo dessa politica a favor das crianças e dos adolescentes evidenciando nas práticas do sistema de justiça a forma como a igualdade juridica é construida no Brasil.

Para compreender essa questão realizou-se um estudo acerca da história das primeiras legislações que fundamentaram o atendimento a esse segmento no Brasil, desde o primeiro Código do Menor até os dias atuais, com a implementação do Estatuto da Criança e do Adolescente, em 1990.

\section{O problema da infância e da juventude pobre no Brasil}

Lidar com crianças e adolescentes que não estavam inseridos no mundo do trabalho ou na escola se tornou uma questão social a ser resolvida no Brasil no século XX. Assim, a construção de uma política de atendimento a "questão do menor" surge em resposta ao problema urbano causado pela industrialização. A presença de crianças e adolescentes pobres nas ruas contrastava com o ideal de ordenamento da cidade e a demanda pela ampliação de mão de obra assalariada. Com o objetivo de conter essa questão, em 1923 foi criado o Primeiro Juizado de Menores do Brasil, que dedicava-se a "analisar jovens negros e pobres acusados dos crimes contra a propriedade" (Batista 2003, 70), e é nesse contexto que a palavra "menor" passa a ser construída no imaginário social associada a crianças pobres que são tuteladas pelo Estado.

Influenciada por questões higienistas e juridicas baseadas no debate internacional de proteção e assistência ao menor, em 1927 o primeiro
Código de Menores propôs ideias correcionais e disciplinares como a proteção legal até os 18 anos de idade, a liberdade vigiada, o fim da questão do discernimento, utilizada pelos juizes para determinar a culpabilidade dos menores, como medidas de combate à criminalidade infantil, segundo Rizzini (2011). A intervenção no "abandono moral", com a possibilidade de suspensão ou extinção do pátrio poder pelos pais sobre o menor também foi apresentado pelo documento. Entende-se por "abandono moral" citado pelo Código de 1927 a convivência de menores pobres nas ruas, vistos como espaços de "perigo moral", com individuos indesejáveis, como prostitutas, bêbados e vagabundos, além da falta de referência de moralidades do trabalhador por parte da familia. Tal condição de influência degradante e ausência moral segundo o Estado seriam condições propícias a formar delinquentes (Gregori 2000, 61). Nesse sentido, o direito tutelar do Estado era caracterizado por conjugar os procedimentos jurídicos dos "menores infratores" e os "abandonados", transformando a infância em objeto das intervenções judiciais. o controle dos "desvios" de crianças e adolescentes que representavam um risco a ordem social era justificado, sendo a garantia de direitos constitucionais irrelevante pois estes não eram detentores de direitos (Silva 2011, 81).

O Código Penal de 1940 foi o próximo passo na construção das políticas de atendimento à crianças e aos adolescentes. Suas principais mudanças foram a responsabilidade penal aos 18 anos de idade, alterando o Código de Menores de 1927, e a criação, em 1941, do Serviço de Assistência ao Menor (SAM) através do Decreto-lei n. ${ }^{\circ}$ 3.733/41, ligado ao Ministério da Justiça. O órgão (SAM) seria o responsável por sistematizar e orientar os serviços de atendimento aos adolescentes "desvalidos" e "delinquentes" (Paula 2011, 39). No entanto, o autoritarismo, o clientelismo e o paternalismo, característicos do Estado Novo tornaram-se as suas principais caracteristicas, o que the consolidou como um órgão repressor de atendimento ao "menor" com o entendimento da internação como o mecanismo mais eficaz para 
a recuperação do menor, não investido no apoio material e educacional da criança e do adolescente, mas acreditando que por meio da repressão e correção através do trabalho a personalidade do adolescente poderia ser reconstruída. Embora com uma nova linguagem essa legislação continua pautada na concepção de uma mesma perspectiva punitiva e correcional pelo trabalho.

Ao longo da Ditadura Militar, novas mudanças para o setor foram implementadas a partir das discussões sobre os direitos humanos. Em 1964. o SAM foi substituído pela Política Nacional do Bem-Estar (PNBEM), sob a Lei n. ${ }^{\circ} 4.513 / 64$ foi criada a Fundação Nacional para o Bem Estar do Menor (Funabem), como órgão ligado diretamente à Presidência da República, as Fundações Estaduais do Bem Estar do Menor (Febem), como órgão executor estadual. Na proposta da política nacional, a Febem seria a responsável por promover a integração social de crianças e adolescentes através de programas e providencias para prevenir a marginalização e o desajustamento. No entanto, esta política herda do SAM tanto o espaço físico e os funcionários, como principalmente as sensibilidades legais que orientam as classificações e categorias do que é justo, moralmente correto e justificável (Mota 2010), com as ações dos atores pautada no autoritarismo e tendo a tutela pelo encarceramento tanto dos "abandonados" e como dos infratores como sua principal ação para corrigir e prevenir o desajustamento (Paula 2013, 252).

A ênfase no encarceramento pode ser observada pela quantidade de unidades construidas para a internação de menores como pelo excesso população de adolescentes encarcerados no território nacional, problema que ainda persiste no cenário atual. Segundo Batista (2003, 78), o governo federal construiu por meio de propaganda ideológica em nível nacional o discurso que fortalecia as representações negativas da juventude pobre e que disseminavam a cultura do medo social, o que para o governo era suficiente para justificar o encarceramento juvenil e a criminalização desse segmento. O Código de Menores de 1979 continua sem mencionar direitos referentes às crianças e aos adolescentes, sendo novamente o menor objeto de tutela do Estado e sem direito à defesa nos procedimentos judiciais.

As lutas dos movimentos sociais a partir de 1980 pela redemocratização do País permitiram que novas discussões sobre a criança e o adolescente se articulassem com base nos debates internacionais acerca dos direitos que deveriam ser assegurados, desempenhando um papel primordial de debate e denúncia das práticas de tortura e violência dentro das instituições de internação. Com a Convenção das Nações Unidas sobre os Direitos da Criança iniciou-se a construção da garantia dos direitos da criança e do adolescente no País, se concretizando pelo dispositivo legal de implementação do Estatuto da Criança e do Adolescente (ECA) em 1990, pela Lei Federal n. 8.069/90. Ele elabora um novo paradigma de atenção e proteção à criança e ao adolescente, como sujeitos de direito e cidadãos constituindo-se como um marco legal e político e estabelecendo responsabilidades e limites ao Estado, aos Juizados, à familia e à sociedade. A Doutrina de Proteção Integral apresentada pelo ECA define crianças e adolescentes como indivíduos em condição peculiar de desenvolvimento físico, mental, moral, espiritual e social, o que limita que sejam considerados como adultos (Paula 2013, 253), porém os apresenta como prioridade das ações da familia, do Estado e da Sociedade.

Com relação às crianças e adolescentes em situação de negligência e em conflito com a lei, o ECA contribui para um importante rompimento com a legislação anterior (Código de Menores de 1979) ao alterar os termos "menor" e "delinquente" para infrator e ao retirar o que denominava-se como "situação irregular", assim distinguindo o ato infracional do desamparo social. Se considerarmos a construção simbólica do termo "menor" e "delinquente" associada à marginalização da juventude pobre, a alteração do termo significa um grande avanço no debate dos direitos de crianças e de adolescentes ao propor reconfigurar os significados que informam as ações dos atores, ou seja, as sensibilidades jurídicas que influenciam as ações legais. 
Outro avanço no texto da legislação é a diferença entre atos infracionais e desamparo social feita através da distinção das medidas protetivas e das medidas socioeducativas, sobre os adolescentes em conflito com a lei ao propor um sistema de garantia de direitos e criar um "especial direito penal juvenil" segundo Silva (2011, 90). Neste artigo nos ocuparemos em refletir sobre as medidas socioeducativas previstas pelo ECA.

\section{A cidadania e a aplicação de medidas socioeducativas}

De acordo com o ECA e o Sistema Nacional de Atendimento Socioeducativo (Sinase), implementado como um documento de orientação em 2006 pelo Conselho Nacional dos Direitos da Criança e do Adolescente (Conanda), o projeto pedagógico de implementação desse sistema socioeducativo, visa orientar-se em ações educativas e reintegrantes dos jovens ao meio social, ao promovê-lo socialmente, contribuindo para sua formação, por meio do acesso à educação e à profissionalização, considerando a sua singularidade e a sua condição de sujeito em desenvolvimento, destacando o convívio familiar e comunitário durante esse processo.

O ECA assegura aos adolescentes infratores os princípios constitucionais do processo legal, assim como afirmam que a privação de liberdade tem caráter provisório e excepcional, sendo aplicável em casos de ato infracional cometido mediante grave ameaça ou violência ou necessidade de garantir a ordem pública ou a integridade física do adolescente.

No entanto, a construção do ECA no Brasil incorporou duas tendências que são apresentadas como antagônicas: os Modelos de Proteção Administrativa e os Modelos da Penalidade Judicial (Nogueira Neto 1998). Embora a legislação enfatize a necessidade de adotar medidas socioeducativas mediante às peculiaridades apresentadas pelo
ECA, optou-se por um atendimento que pode ser classificado como judicial-administrativo em que o adolescente em conflito com a lei é submetido às sanções legais do Judiciário, que é responsável por aplicar as medidas socioeducativas que deverão ser cumpridas administrativamente em unidades de internação. No entanto, tais unidades submetem-se ao rígido controle do Poder Judiciário e dos Conselhos da Criança e do Adolescente.

O Estatuto da Criança e do Adolescente prevê a inimputabilidade e não a irresponsabilidade de adolescentes que cometem ato infracional (Abdala 2013, 69). Dessa forma, crianças e adolescente não são penalizados como adultos por praticar ato infracional; são inimputáveis. Porém o adolescente, embora não receba pena, será sujeito a medidas socioeducativas, como: advertência; obrigação de reparar o dano; prestação de serviços à comunidade; liberdade assistida; inserção em regime de semiliberdade; internação em estabelecimento educacional; além de qualquer uma das medidas de proteção previstas no art.101, I a VI (Eca 1990).

De acordo com o Levantamento do Sinase, em 2011 era possivel observar um crescimento de $10,69 \%$ (de 17.703 para 19.595) no número de adolescentes em restrição e privação de liberdade em relação ao ano anterior, sendo que as medidas de internação obtiveram um aumento de 10,97\% (de 12.041 para 13.362); ${ }^{2}$ o que demonstra uma tendência no crescimento entre as Medidas socioeducativas de restrição e privação de liberdade. ${ }^{3}$ Considerando a proposta do ECA sancionada em 1990 que propõe um projeto de refundação das relações sociais de crianças e de adolescentes e a familia, a comunidade e o Estado (Paula 2011, 56), o aumento das taxas de restrição e privação da liberdade sinalizam um caminho contrário ao que se propõe a lei.

Os dados divulgados pela Defensoria Pública do Rio de Janeiro, com base no relatório sobre

\footnotetext{
2 Em internação provisória houve um aumento de 9,68\% (de 3.934 para 4.315); e em semiliberdade de 11,00\% (de 1.728 para 1.918), segundo a Sinase (2011).

3 O artigo 112 do Estatuto da Criança e do Adolescente apresenta as medidas socioeducativas previstas ao adolescente em casos de prática de atos infracionais, sendo Advertência, Obrigação de reparar o dano, Prestação de serviço à Comunidade; medidas consideradas leves e realizadas meio aberto; enquanto a Liberdade Assistida, Inserção em regime de semiliberdade; medidas restritivas da liberdade: e por fim, a Internação em estabelecimento educacional, como medida de privação de liberdade.
} 
os questionários das audiências de apresentação realizadas entre junho de 2016 e maio de 2017 no Núcleo de Audiência de Apresentação (NAAP) nos permitem fazer algumas considerações sobre a aplicação das medidas socioeducativas no estado e a ideia de cidadania que o ECA propõe. Foram analisados nesse relatório 2.393 questionários, sendo 2.254 adolescentes do sexo masculino (94,1\%), 131 do sexo feminino $(5,4 \%)$ e 8 transgêneros (0,3\%).

Considerando a cidadania a partir das ideias que Marshall (1967) nos apresenta e as suas dimensões, podemos considerar como o cidadão pleno aquele que possui direitos sociais, civis e políticos, que nos permitem ser tratado igualmente mesmo diante das distinções econômicas causadas pelo mercado. Com base nessas dimensões, faremos uma reflexão sobre a garantia da cidadania de crianças e de adolescentes no Rio de Janeiro.

A começar pelos direitos civis, enquanto direitos fundamentais à vida como a liberdade, a propriedade, a igualdade perante a lei, esses são os primeiros que podemos questionar na situação dos adolescentes atendidos pelas medidas de privação de liberdade no estado do Rio de Janeiro. A superlotação das instituições de internação de jovens infratores reflete a contradição na forma como o Estado lida com a aplicação das medidas socioeducativas e a liberdade. Com a análise de $83 \%$ do total de questionários que apresentavam a informação sobre o resultado da audiência, 1.284 apresentavam indicação de internação provisória. Ao optar pela internação em maior escala e restringir a liberdade, apesar do ECA os reconhecer como indivíduos em situação peculiar de desenvolvimento e que são penalmente inimputáveis, a aplicação das regras traz a qualificação dos sujeitos sob uma dimensão moral (Trévenot 2006). Nessa perspectiva, a aplicação das medidas socioeducativas conserva um caráter de normatização do controle sociopenal dos adolescentes, que o Código de Menores de 1979 já possuía a intenção de estabelecer. A admissão do adolescente como sujeito de direitos está condicionada a decisão do juiz em incluí-lo socialmente ou operar medidas que levam à sua exclusão.

Outro direito a ser avaliado são os sociais, que correspondem a possibilidade de reduzir os excessos de desigualdade produzidas pelo mercado (Carvalho 2001) pautado na ideia de justiça social, com a oferta de educação, saúde, trabalho e o mínimo de bem-estar.

No Rio de Janeiro o sistema socioeducativo opera com o déficit superior a 600 vagas e com histórico de superlotação, segundo nota da Defensoria Pública do Rio de Janeiro. A superlotação das instituições de internação não contribui com o cumprimento dos direitos do adolescente privado de liberdade previstos no art. 124 do ECA que assegura a obrigatoriedade de atividades pedagógicas, entre tantos outros direitos, com o objetivo de reintegrar os jovens à sociedade. Como explicitou a DPRJ tais atividades pedagógicas ficam em segundo plano, em um cenário em que a contenção e o ordenamento dos jovens se constituem prioridade. Além disso, como apresentou Paula (2013, 258-262) os jovens em liberdade assistida enfrentam dificuldades de inserção no ambiente escolar e no trabalho, o que inviabiliza a sua inclusão na comunidade política.

O adolescente submetido à internação em instituições superlotadas enfrentará dificuldades iguais ou maiores na sua reintegração à sociedade, pois o ato infracional cometido resulta não apenas na expulsão do grupo, mas da condição de humanidade (Geertz 2007). A dificuldade da ressocialização fica evidente na reincidência dos adolescentes no sistema de internação do Rio de Janeiro. Os questionários da DPRJ demonstram que, entre os adolescentes, 1.023 (44,44\%) responderam a outros processos na Vara de Infância, e 520 disseram que já estiveram acolhidos (27,96\%) em instituições. Embora o projeto do ECA seja um conjunto de diretrizes para garantir direitos fundamentais à cidadania, o Sistema de Justiça Juvenil perpetua uma lógica de exclusão social de jovens pobres, em sua maioria negros e com baixa escolaridade.

Por fim, os direitos políticos que sugerem a participação do cidadão no governo da sociedade (Carvalho 2001) e que no Brasil especificamente se traduz por direito ao voto também constituem limitações à cidadania juvenil. Os jovens em internação não exercem o direito ao voto, da mesma 
forma como a reclusão impede a participação na organização política da sociedade local. Nessa perspectiva, a proposta de transformar crianças e adolescentes em cidadãos com direitos e deveres torna-se deficitária, pois depende da ação conjunta entre outros atores sociais que podem gerar a inclusão, como também acentuar a exclusão de direitos e o exercício da cidadania (Paula 2013, 262).

Observa-se que as garantias legais do direito de crianças e adolescentes como maneira de assegurar a formação do indivíduo social e conferir um status de cidadão, limita-se ao campo jurídico, à medida que o exercício concreto da cidadania continua inoperante. $O$ direito à cidadania no Brasil, nas dimensões que foram apresentadas por Marshall (1967), beneficiam apenas uma parcela da população, sendo os privilegiados os que possuem recursos financeiros e maior acesso à educação. A escassez de direitos sociais e civis constituem um desafio a cidadania (Carvalho 2001) e principalmente a crianças e adolescentes expostos a conflitos e tensões sociais.

O caso Brasileiro possui uma formação peculiar como destacou Damatta (1995) em que a noção de cidadão em situações sociais diferentes resulta em práticas sociais e tratamentos diversos, em uma espécie de cidadania que, embora reconhecida e definida formalmente pela Lei e pelo Estado, constrói-se a partir de espaços relacionais, "a casa e a rua" (Damatta, 1995, 71104). Tais categorias sociológicas no Brasil não simbolizam espaços geográficos, elas distinguem entre público e privado e as moralidades acionadas por elas (Damatta 1995). Dessa forma a sociedade brasileira administra seus conflitos com base nas relações e busca hierarquizar os atores envolvidos. Assim, indivíduo (ou cidadão) que não tem uma relação de prestígio, ocupa um lugar inferior na hierarquia e será tratado pelo sistema legal formal, o que explica a ideia de uma cidadania às avessas segundo o autor.

\section{Considerações Finais}

Com o objetivo de contribuir ao debate sobre os direitos da criança e do adolescente e a ideia de Cidadania, apresentada pelo Estatuto da Criança e do Adolescente, observamos a aplicação das medidas socioeducativas no Estado do Rio de Janeiro, considerando o momento atual de superlotação dos espaços de internação juvenil e a construção social de estereótipos depreciativos sobre os "menores" e a ideia de redução da maioridade penal.

A retrospectiva das ações institucionais sobre a infância e a juventude no Brasil nos permitem observar a construção do estigma do "menor delinquente" e da tutela do Estado sobre a população juvenil pobre das cidades que culminou em políticas de atendimento a criança e ao adolescente como controle dos desvios e da manutenção da ordem social por meio do encarceramento.

Uma análise do Relatório da DPRJ, considerando o crescimento das internações e do número de adolescentes atendidos por esse sistema socioeducativo, mostra que o perfil desses se caracteriza por adolescentes oriundos de familias pobres, negros e com baixo grau de instrução, consequentemente os excluidos do mercado de trabalho. Embora a implementação do ECA preveja a internação sob condição de excepcionalidade e procure não causar a privação de liberdade (parcial ou total) ao adotar a proteção integral e a garantia de direitos aos adolescentes, o perfil dos adolescentes em conflito com a lei não se modificou, da mesma forma como as dimensões repressivas e punitivas que orientavam as práticas.

Ao estabelecer cidadania a crianças e adolescentes sob a condição de arcarem juridicamente com a responsabilidade penal dos seus atos, estabelecemos de forma legitima o encarceramento de crianças e de adolescentes. Como um dispositivo legal, o Estatuto da Criança e do Adolescente implementou diversas mudanças, mas não tem sua aplicação integral na realidade, assim, as medidas socioeducativas continuam sendo uma forma de tutela do Estado e supressão do direito à cidadania. A responsabilização pelos atos infracionais e a criminalização da pobreza marcam as aplicações das medidas socioeducativas, que por sua vez revelam a tendência ao aspecto punitivo que ainda permanece.

Como foi possivel observar, a cidadania é pautada nas relações hierarquizadas da qual ficam 
excluídos os jovens que apresentam maior vulnerabilidade social, que ao ingressar no sistema de medidas socioeducativas serão responsabilizados pelo sistema penal juvenil. Dessa maneira, mesmo que a legislação torne formalmente crianças e adolescentes em cidadãos de direitos, tal cidadania está condicionada aos vínculos sociais que esses estabelecem, com poder de determinar a distinção entre os menores infratores e os cidadãos de direitos. Igualdade juridica no tratamento dos conflitos é tratar desigualmente os desiguais, já que a aplicação das normas juridicas é particularizada com base em uma estrutura hierárquica e inquisitorial (Fonseca 2005).

\section{Referências}

Abdala, Janaína de Fátima Silva. 2013. Aprisionando para educar adolescentes em conflito com a lei: memória, paradoxos e perspectivas. Tese (Doutorado em Educação) - PPGE/Universidade Federal Fluminense.

Amorim, Maria Stella; Roberto Kant de Lima, Regina Teixeira Mendes organizadores. 2005. Ensaios sobre a Igualdade Jurídica: acesso à justiça criminal e direitos de cidadania no Brasil. Rio de Janeiro: Lúmen Júris.

Batista, Vera Malaguti. 2003. Difíceis ganhos fáceis: Drogas e juventude pobre no Rio de Janeiro. 2. ed. Rio de Janeiro: Editora Revan.

Brasil. Estatuto da Criança e do adolescente: Lei n.8069, de 13 de julho de 1990, e legislação correlata. São Paulo: Secretaria Municipal de Direitos Humanos e Cidadania. 2016.

Carvalho, José Murilo de. 2001. Cidadania no Brasil: o longo caminho. Rio de Janeiro: Civilização Brasileira.

Damatta, Roberto. 1985. Cidadania: a questão da cidadania num universo relacional. In: A casa e a rua: espaço, cidadania, mulher e morte no Brasil, São Paulo: Brasiliense. 71-104.

Fonseca, Regina Lúcia Teixeira M. de. 2005. Igualdade à Brasileira: cidadania como instituto jurídico no Brasil. In: "Ensaios sobre a Igualdade Juridica: acesso à justiça criminal e direitos de cidadania no Brasil", Maria Stella Amorim, Roberto Kant de LIMA, Regina Teixeira Mendes organizadores. Rio de Janeiro: Lúmen Júris. 1-34.

Geertz, Clifford. 2007. O Saber local: fatos e leis em uma perspectiva comparada. In: O Saber Local. 9 ed. 249-356. Petrópolis: Vozes.

Gregori, Maria Filomena. 2000. Viração. São Paulo: Companhia das Letras.

Levantamento Nacional do Atendimento Socioeducativo. 2011. Acesso em: 13 de Maio de 2019. http://www. mp.rs.gov.br/infancia/estudos/id423.htm.
Marshall, T. H. 1967. Cidadania e Classe Social e Status. Rio de Janeiro: Zahar.

Mota, Fábio Reis. 2010. Cidadãos em toda parte ou cidadãos à parte? Demandas de direitos e reconhecimento no Brasil e na França. Tese (Doutorado em Antropologia) - PPGA/Universidade Federal Fluminense.

Neto, Wanderlino Nogueira. 1998. Responsabilização Jurídica do adolescente em conflito com a lei, a partir do ordenamento jurídico brasileiro. Brasilia: Ministério da Justiça

Paula, Liana de. 2013. Cidadania no atendimento socioeducativo: o paradoxo da garantia formal de direitos dos adolescentes pobres. In: Sensibilidades Juridicas e Sentidos de Justiça na Contemporaneidade. Interlocução entre Antropologia e Direito, Kátia S.S. Mello, Fábio R. Mota e Jacqueline Sinhoreto (Orgs.), 245-264. Niterói, EDUFF.

Paula, Liana de. 2011. Liberdade Assistida: punição e cidadania na cidade de São Paulo. Tese (Doutorado) São Paulo: Departamento de Sociologia - FFLCH/USP.

Relatório de um ano sobre os questionários das audiências de apresentação realizadas entre junho 2016 e maio de 2017. http://www.tjr.jus.br/web/guest/ home//noticias/visualizar/34013?p_p_state=maximized, acesso em 01 de novembro de 2017.

Rizzini, Irene. 2011. A arte de governar crianças: a história das políticas sociais, da legislação e da assistência à infância no Brasil. 3. ed. São Paulo: Cortez.

Silva, Maria Liduina de Oliveira e. 2011. Entre proteção e punição: o Controle sociopenal dos Adolescentes. São Paulo: Unifesp.

\section{Francielly Silva Costa Alves Rocha}

Bacharel em Ciências Sociais pela Universidade do Estado do Rio de janeiro (UERJ), no Rio de Janeiro, RJ, Brasil. Mestranda pelo Programa de Pós-Graduação em Antropologia (PPGA) da Universidade Federal Fluminense (UFF), em Niterói, Brasil; e pesquisadora do Grupo de Estudos e Pesquisa em Antropologia do Direito e das Moralidades (Gepadim), vinculado ao Núcleo Fluminense de Estudos e Pesquisa (Nufep), da UFF. 